\title{
POLA MANAJEMEN DISTRIBUSI KOMPETENSI HOTS DALAM PEMBELAJARAN AKIDAH AKHLAK (Analisis KMA No. 165 TAHUN 2014)
}

\author{
Ahmad Dwi Nur Khalim \\ Fakultas Keguruan dan Ilmu Pendidikan \\ Universitas Mercu Buana Yogyakarta \\ Email:ahmadkhalim55@gmail.com
}

\begin{abstract}
Abstrak
Tantangan pendidikan semakin komplek. Tantangan terbaru tentang pembelajaran abad 21. Tuntutan wacana ini diantaranya critical thinking. Sehingga pembelajaran Higher Order Thinking Skill (HOTS) penting adanya. Penelitian ini bertujuan melihat pola manajemen distribusi kompetensi dasar ranah HOTS yang ada dalam KMA Nomor 165 Tahun 2014 Tentang Kurikulum 2013 Mata Pelajaran PAI dan Bahasa Arab Pada Madrasah. Penelitian ini bersifat pustaka. Metode menganalisis data menggunakan metode deskriptif, datanya diperoleh dengan teknik dokumentasi. Untuk memfokuskan penelitian, peniliti menggunakan analisis isi. Hasil penelitian menunjukan Kompetensi Dasar (KD) didominasi tingkat memahami (C2), kemudian mengingat (C1) dan menerapkan (C3). Sementara level HOTS menganalisis (C4) sebagai tingkatan awal HOTS jumlahnya masih sedikit dibanding C2, C1, dan C3. level menganalisis (C4) hanya berjumlah 22 KD. Sementara mengevaluasi (C5) serta mencipta (C6) belum sama sekali. Pola distribusinya semkain tinggi jenjang semakin banyak kompetensi dasar ranah HOTS nya. Ataupun sebaliknya semakin rendah jenjang semakin sedikit kompetensi dasar ranah HOTS nya.
\end{abstract}

\section{Kata Kunci: Distribusi, Kompetensi Dasar, HOTS, Akidah Akhlak}

\begin{abstract}
The challenges of education are increasingly complex. The latest challenge about 21st century learning. Tuntutan wacana ini diataranya critical thinking. So learning the Higher Order Thinking Skill (HOTS) is important. This study aims to look at the pattern of distribution of basic competencies in the HOTS domain in KMA Number 165 of 2014 concerning the 2013 curriculum of PAI and Arabic subjects in Madrasah. This research is literature. The method of analyzing data using descriptive methods, the data obtained by documentation techniques. To focus the research, researchers used content analysis. To focus the research, researchers used the results of the study to show that Basic Competence $(K D)$ was dominated by the level of understanding $(C 2)$, then remembering (C1) and applying (C3). While the HOTS level analyzing $(C 4)$ as the initial level of HOTS is still small compared to $C 2, C 1$, and C3. the level of analyzing (C4) is only $22 \mathrm{KD}$. As for evaluating (C5) and creating (C6) not yet. The pattern of distribution at the higher levels is more and more basic competencies in the HOTS domain. Or vice versa the lower the level the less basic competence of the HOTS domain.
\end{abstract}

Keywords: Distribution, Basic Competence, HOTS, Morals 


\section{PENDAHULUAN}

Tantangan kehidupan bagi sekolah semakin komplek. Baru-baru ini muncul wacana pembelajaran abad 21. Wacana ini menggaungkan istilah $4 \mathrm{C}$, dan $\mathrm{C}$ salah satunya adalah critical thingking. Tak urung dunia pendidikan harus bisa membaca arah wacana ini. Bukan pekara mudah memang bagi dunia pendidikan untuk membaca dan menganalisis tantangan di era disrupsi ini. Tapi juga sebaliknya jika sekolah atau lembaga pendidikan tidak punya daya nalar kritis sudah dapat dipastikan mereka akan terlindas oleh jaman.

Inilah tantangan nyata bagi pendidikan formal. Apakah pendidikan hanya membekali ijazah atau gelar saja bagi siswanya? Harusnya tidak!!! Sekolah harus sadar untuk membiasakan anak berpikir tingkat tinggi. Namun sayangnya pemerintah sebagai pembuat kebijakan juga belum pada tingkat kesadaran tersebut. kompetensi yang distandarkan belum mengarah pada Higher Order Thinking (HOT). Inilah problem awal dari ketidak bermaknaan pendidikan. Anak merasa belajar dikelas membosankan, jenuh dan merasa kurang bermanfaat bagi kehidupnnya. Akibatnya ialah ada anak melampiasakan energi ke hal negatif, belajar dikelas mengantuk, bahkan guru tidak hargai dikelas.

Tidak hanya itu, fakta bahwa kualitas peserta didik kita sangat memprihatinkan juga menjadi alasan kenapa pembelajaran HOTS penting untuk segera ditindaklanjuti. Merujuk hasil study PISA (Programme for International Student Assessment) menunjukan bahwa pada umumnya kemampuan peserta didik Indonesia sangat rendah dalam : (1) memahami informasi yang komplek; (2) teori, analisis dan pemecahan masalah; (3) pemakaian alat, prosedur dan pemecahan masalah; dan (4) melakukan Investigasi. Keempat kemampuan itu dikenal dengan kemampuan berfikir tingkat tinggi atau Higher Order Thinking Skills (HOTS). ${ }^{1}$

Sudah seharusnya pendidikan mulai mempersiapkan bagaimana pembelajaran yang mengarah ke HOTS. Desain pembelajaran yang tertuang dalam rencana proses pembelajaran sudah harus diarahkan ke HOTS. Nantinya dalam proses pembelajaran dan evaluasinya juga akan otomatis mengarah pada HOTS. Karena tidak adil rasanya kalau proses pembelajaran belum HOTS tapi evaluasi nya sudah pada level HOTS. Maka dari itu sudah sewajarnya kalau guru dan pemerintah bekerjasama dalam menyiapkan yang HOTS. Dan bekerja sama untuk menyiapkan pembelajaran yang mengarah ke HOTS.

Sementara mata pelajaran akidah akhlak, adalah titik awal untuk mendasari HOTS. Adanya pembiasaan HOTS dalam pembelajaran akidah akhlak akan membekali siswa dalam berperilaku. Ketika akhlak sudah tertanam dengan mantap dan baik, melalui proses pembelajaran HOTS. Maka dapat dipastikan bahwa perilaku anak pada matapelajaran yang lain juga baik. Inilah awal untuk mencetak generasi-generasi hebat dimasa yang mendatang. Generasi yang didadanya tertanam akhlak mulia dan cerdas intelektualnya.

Disinilah kemudian penulis tertarik untuk mengkaji KMA No.165 Tahun 2014 Tentang Kurikulum 2013 Mata Pelajaran PAI dan Bahasa Arab Pada Madrasah. Peneliti ingin melihat pola manajemen distribusi kompetensi dasar ranah HOTS pada semua jenjang. Mulai dari jenang sekolah dasar atau madrasah Ibtidiyah sampai jenjang

\footnotetext{
1 https://www.kompasiana.com/darwonogurukita/5836d9dd537b610c0b8e6d20/higher-order-thinkingskills-guru?page=all. diakses tanggal 14 November 2018, pada pukul 15.37 WIB.
} 
madrasah aliyah. Harapannya dengan penelitian ini bisa membantu lembaga pendidikan khususnya madrasah untuk bisa menyiapkan pembelajaran dan capaian HOTS.

\section{METODE PENELITIAN}

Jenis Penelitian Penelitian ini adalah bersifat pustaka (library research). Dalam library research ini peneliti menganalisis isi dari Keputusan Mentri Agama Nomor 165 Tahun 2014 Tentang Kurikulum 2013 Mata Pelajaran PAI dan Bahasa Arab Pada Madrasah. Dalam hal ini peneliti memanfaatkan riset pustaka yang mana tidak sekedar membaca dan mencatat literatur yang telah ada, tetapi juga melakukan penelitian dan mengolah data yang berkenaan dengan Kompetensi Inti dan Kompetensi Dasar

Dalam hal ini peneliti ingin melihat persebaran kompetensi dasar kategori HOTS (Higher Order Thingking Skill). Teknik pengumpulan data dari penilitian ini yaitu teknik dokumentasi, merupakan teknik pengumpulan data yang yang dapat diperoleh dari selain manusia. Dengan teknik ini akan diperoleh data bersifat deskriptif-kualitatif. ${ }^{2}$ Dimana data ini dikumpulkan dengan menelaah KMA Nomor 165 dan menganalisisnya dengan teori Higher Order Thinking Skill (HOTS). Teori yang digunakan adalah teori dari Anderson \& Karthwhol. Teori yang menjadi acauan adalah sebagai berikut:

$\mathrm{C} 1$ : Mengingat artinya mendapatkan kembali atau pengambilan pengetahuan relevan yang tersimpan dari memori jangka panjang.

C2: Memahami, mendeskripsikan susunan dalam artian pesan pembelajaran, mencakup oral, tulisan, dan komunikasi grafik.

C3: Menerapkan, menggunakan prosedur dalam situasi yang dihadapi.

C4:Menganalisis, memecah materi menjadi bagian-bagian pokok dan menggambarkan bagaimana bagian-bagian tersebut, dihubungkan satu samalain maupun menjadi sebuah struktur keseluruhan atau tujuan.

C5: Mengevaluasi atau menilai, melakukan evaluasi atau penilaian yang didasarkan pada kriteria dan atau standar.

C6: Menciptakan, menempatkan bagian-bagian secara bersama-sama ke dalam suatu ide, semuanya saling berhubungan untuk membuat hasil yang baik. ${ }^{3}$

Anderson \& Karthwhol berpendapat bahwa indikator berpikir tingkat tinggi meliputi 3 kata kerja operasional. Ketiga kata tersebut adalah menganalisis (C4), menilai/ mengevaluasi (C5) dan mencipta (C6). Dapat ditarik kesimpulan bahwa kemampuan berpikir dasar mencakup proses dasar (basic processes) yang merupakan gambaran dari proses berpikir rasional yang mengandung sekumpulan proses mental dari yang sederhana menuju kompleks. Sementara berpikir kompleks atau kemampuan berpikir tingkat tinggi (HOTS) merupakan kemampuan menghubungkan, memanipulasi, dan mentrasformasi pengetahuan serta pengalaman yang sudah dimiliki untuk berpikir kritis dan kreatif dalam upaya menentukan keputusan dan memecahkan masalah pada situasi baru. ditambahkan juga bahwa Berdasarkan beberapa pendapat tersebut dapat ditarik kesimpulan bahwa kemampuan berpikir tingkat tinggi merupakan proses berpikir yang tidak sekedar menghafal dan menyampaikan kembali informasi yang diketahui peserta didik. Kemampuan berpikir tingkat tinggi merupakan kemampuan menghubungkan,

Irawan,Suhartono, Metode Penelitian Sosial. (Bandung: Remaja Rosdakarya. 2008).,hlm.70

Wowo Sunaryo Kuswana, Taksonomi Kognitif, (Bandung: Remaja Rosdakarya Offset,2012), hlm.114115 
memanipulasi, dan menstransformasi pengetahuan serta pengalaman yang sudah dimiliki untuk berpikir secara kritis dan kreatif dalam upaya menentukan keputusan dan memecahkan masalah pada situasi yang baru dan itu semua tidak dapat dilepaskan dari kehidupan sehari-hari. ${ }^{4}$

Menurut Karthwol dalam lewy indikator untuk mengukur kemampuan berpikir tingkat tinggi adalah: (a) Membuat generalisasi suatu ide atau cara pandang terhadap sesuatu. (b) Merancang suatu cara untuk menyelesaikan masalah. (c) Mengorganisasikan unsur-unsur atau bagian-bagian menjadi struktur baru yang belum pernah ada sebelumnya.

Sumber data dalam penelitian adalah KMA. ${ }^{5}$ Teknik Analisis Data dalam penelitian ini ditujukan untuk menentukan fokus penelitian, apa yang harus digali dan memastikan keabsahan. ${ }^{6}$ Adapun metode yang digunakan dalam menganalisis data adalah Metode Deskriptif. Tujuan metode analisis data ini adalah mendeskripsikan KI-KD dalam KMA Nomor 165 dan memetakan nya sesuai jenjang pendidikan.

Kemudian, sumber primer data dalam penelitian ini adalah KMA No.165 Tahun 2014 Tentang Kurikulum 2013 Mata Pelajaran PAI dan Bahasa Arab Pada Madrasah. KMA No.165 dipilih, karena menjadi rujukan dalam pengembanagan materi ataupun lebih umumnya bahan ajar. Dengan demikian data primer akan diperoleh secara langsung dari rancangan KMA No. 165 dan menganalisisnya dengan teori Higher Order Thinking Skill (HOTS) dari Anderson dan Karthwhol.

Selanjutnya metode analisis data, metode analisis data adalah proses mengorganisasikan dan mengurutkan data kedalam pola, kategori, dan satuan uraian dasar sehingga dapat ditemukan tema dan dapat dirumuskan hipotesis kerja seperti yang disarankan oleh data. ${ }^{7}$ Sementara metode yang digunakan dalam penelitian ini adalah teknik dokumentasi. Teknik dokumentasi merupakan teknik pengumpulan data yang yang dapat diperoleh dari selain manusia. ${ }^{8}$ Dengan teknik dokumentasi akan diperoleh data bersifat deskriptif-kualitatif. Untuk menganalisa data yang diperoleh dari hasil penelitian, penulis menggunakan metode penelitian deskriptif. Metode deskriptif ialah metode menganalisa data yang mencoba mencari deskripsi yang tepat dan cukup dari semua aktivitas, objek, proses, dan manusia. ${ }^{9}$ Dalam hal ini rancangan KMA Nomor 165 akan dirujuk kemudian dianalisis sesuia teori dari Anderson dan Karthwhol.

Untuk itu, agar hasil penelitian dapat tersusun sistematis dan terukur, maka langkah peneliti dalam menganalisis data adalah menggunakan metode analisis isi. Analisis isi merupakan penelitian yang membahas isi dari sesuatu secara mendalam, baik itu berupa bahan yang tertulis atau pun bahan yang diucapkan. ${ }^{10}$ Metode analisis isi ini digunakan untuk menganalisa isi yang terdapat dalam KMA Nomor 165. Selain itu, metode ini

Abdul hamid wahid, Integrasi Higher Order Thinking Skill (HOTS) Dengan Model Creative Problem Solving, MODELING: Jurnal Program Studi PGMI Volume 5, Nomor 1, Maret 2018, hlm.88.

5 Suharsimi Arikonto, Prosedur Penelitian; Suatu Pendekatan Praktik (Jakarta: PT Rineka Cipta, 2013), hlm. 172.

6 Nusa Putra dan Santi Lisnawati, Penelitian Kualitatif Pendidikan agama Islam. Bandung: Remaja Rosdakarya. Peraturan Pemenrintah Nomor 32 Tahun 2013 tentang SNP. 2013. hlm.35.

7 Ibid., hlm. 280.

$8 \quad$ Ibid., hlm.70

9 Sulistyo-basuki, Metode penelitian, (Jakarta: Penaku, 2010), hlm. 110.

10 Ibid., hlm.72. 
digunakan untuk memfokuskan penelitian pada bahan yang tersurat dan tersirat dari isi teks dalam buku tersebut. ${ }^{11}$ Metode analisis isi inilah yang nanti akan digunakan menganalisis KI-KD yang terdapat dalam KMA Nomor 165 dan mengaitkannya dengan teori Higher Order Thinking Skill (HOTS)

\section{HASIL DAN PEMBAHASAN}

Berdasar rumusan masalah yang tertuang dalam pendahuluan. Ada beberapa hasil data temuan terkait penelitian pola manajemen distribusi kompetensi ranah HOTS dalam KMA No.165 Tahun 2014 Tentang Kurikulum 2013 Mata Pelajaran PAI dan Bahasa Arab Pada Madrasah. Berikut hasil dan pembahasanya:

Kurikulum pada dasarnya merupakan wadah atau sarana untuk memuat dan mengembangkan visi dan misi yang dimiliki sebuah lembaga pendidikan supaya misi tersebut dapat terimplementasi dengan baik. ${ }^{12}$

Mata Pelajaran Agama Islam merupakan materi penting yang diintegrasikan dengan pelajaran budi pekerti, meskipun pada hakikatnya, agama merupakan sumber inspirasi dan melandasi pelajaran budi pekerti. ${ }^{13}$

KMA No.165 Tahun 2014 Tentang Kurikulum 2013 Mata Pelajaran PAI dan Bahasa Arab Pada Madrasah terdiri dari beberapa BAB. BAB I tentang pendahuluan berisi latar belakang, maksud dan tujuan, sasaran, ruang lingkup, pengertian umum. Kemudian BAB II tentang struktur kurikulum. BAB II ini berisi kompetensi inti, kompetensi dasar kurikulum 2013 di madrasah, mata pelajaran madrasah. Kemudian BAB III tentang standar kompetensi lulusan pendidikan agama islam dan bahasa arab di madrasah ibtidaiyah, Tsanawiyah dan Aliyah. Isi dari BAB III ini adalah pendahuluan, kompetensi lulusan madtasah ibtidayah, kompetensi lulusan madtasah tsanawiyah, kompetensi lulusan madrasah Aliyah. BAB IV berisi tentang standar isi pendidikan agama islam dan bahasa Arab di Madrasah Ibtidayah, Tsanawiyah dan Aliyah. Dalam $\mathrm{BAB}$ ini dibahas tentang kelompok mata pelajaran PAI dan Bahasa Arab, kelompok pelajaran peminatan, mata pelajaran pemilihan lintas kelompok peminatan, tujuan dan ruang lingkup mata pelajaran. BAB $\mathrm{V}$ berisi tentang kompetensi inti dan kompetensi dasar tingkat madrasah ibtidayah, kemudian dilanjutkan kompetensi inti dan kompetensi dasar tingkat madrasah tsanawiyah, dan kompetensi inti dan kompetensi dasar tingkat madrasah aliyah. BAB VI berisi standar proses pendidikan agama islam dan bahasa arab di madrasah ibtidaiyah, tsanawiyah dan aliyah. Dalam BAB ini berisi pandangan tentang pembelajaran, proses pembelajaran terjadi secara internal pada diri peserta didik, pembelajaran langsung dan tidak langsung, perencanaan pembelajaran. BAB VII standar penilaian pendidikan agama islam dan bahasa arab di madrasah ibtidaiyah, tsanawiyah, dan aliyah. Dalam BAB ini dibahas tentang pengertian dasar, prinsip dan pendekatan

11 Eriyanto, Analisis Isi, (Jakarta: Kencana. 2011), hlm.1.

12 Mohammad Muchlis Solichin. "Pendidikan Agama Islam Berbasis Kesetaraan Gender." TADRIS: Jurnal Pendidikan Islam 1, no. 1 (2006), hlm. 56-57.

13 Saiful Hadi. "Inovasi Kurikulum Keagamaan Di SMAN 1 Pamekasan." TADRIS: Jurnal Pendidikan Islam 10, no. 1 (2015): 124. 
penilaian, ruang lingkup, teknik dan instrumen penilaian, mekanisme dan prosedur penilaian, pelaksanaan dan pelaporan penilaian.

Setelah dipaparkan isi KMA No.165 Tahun 2014 Tentang Kurikulum 2013 Mata Pelajaran PAI dan Bahasa Arab Pada Madrasah. Selanjutnya untuk melihat pola manajemen distribusi berikut akan peneliti paparkan hasil analisis KI-KD dalam KMA No.165 Tahun 2014 Tentang Kurikulum 2013 Mata Pelajaran PAI dan Bahasa Arab Pada Madrasah, berkaiatan tingkat berpikir dalam kompetensi mata pelajaran Akidah Akhlak.

Tabel 1. Pola manajemen distribusi Mata Pelajaran PAI dan Bahasa Arab Pada Madrasah

\begin{tabular}{cccccccc}
\hline & CI & C2 & C3 & C4 & C5 & C6 & TOTAL \\
\hline KELAS 1 & 9 & 8 & 4 & 0 & 0 & 0 & 21 \\
\hline KELAS 2 & 10 & 9 & 3 & 0 & 0 & 0 & 22 \\
\hline KELAS 3 & 8 & 10 & 4 & 0 & 0 & 0 & 22 \\
\hline KELAS 4 & 8 & 7 & 5 & 2 & 0 & 0 & 22 \\
\hline KELAS 5 & 9 & 6 & 5 & 0 & 0 & 0 & 20 \\
\hline KELAS 6 & 9 & 5 & 4 & 0 & 0 & 0 & 18 \\
\hline KELAS 7 & 2 & 10 & 6 & 2 & 0 & 0 & 20 \\
\hline KELAS 8 & 1 & 16 & 5 & 2 & 0 & 0 & 24 \\
\hline KELAS 9 & 1 & 12 & 3 & 2 & 0 & 0 & 18 \\
\hline KELAS 10 & 4 & 15 & 1 & 8 & 0 & 0 & 28 \\
\hline KELAS 11 & 1 & 15 & 2 & 4 & 0 & 0 & 22 \\
\hline KELAS 12 & 1 & 14 & 1 & 2 & 0 & 0 & 18 \\
\hline JUMLAH & 63 & 127 & 43 & 22 & 0 & 0 & 255 \\
\hline
\end{tabular}

Dari tabel diatas dapat dianalisa bahwa kompetensi masih didominasi pada level mengingat (CI) dengan jumlah 63, memahami (C2) dengan jumlah 127 dan disusul menerapkan (C3) di angaka 43. Tentunya ketiganya sebgaiamana teori Anderson dan Karthwhol masih pada ranah LOTS (Lower Order Thingking Skill). Sementara untuk HOTS hanya ada pada tingkat menganalisis (C4) yang jumlahnya hanya 22. Sementara pada tingkat mengevalusai (C5) dan mencipta (C6) belum ada sama sekali. Untuk melihat pola manajemen distribusi kompetensi HOTS berikut data diatas akan kita analisis menggunakan model grafik atau diagram batang dan diagram garis. 


\section{Gambar 1. Distribusi kompetensi HOTS}

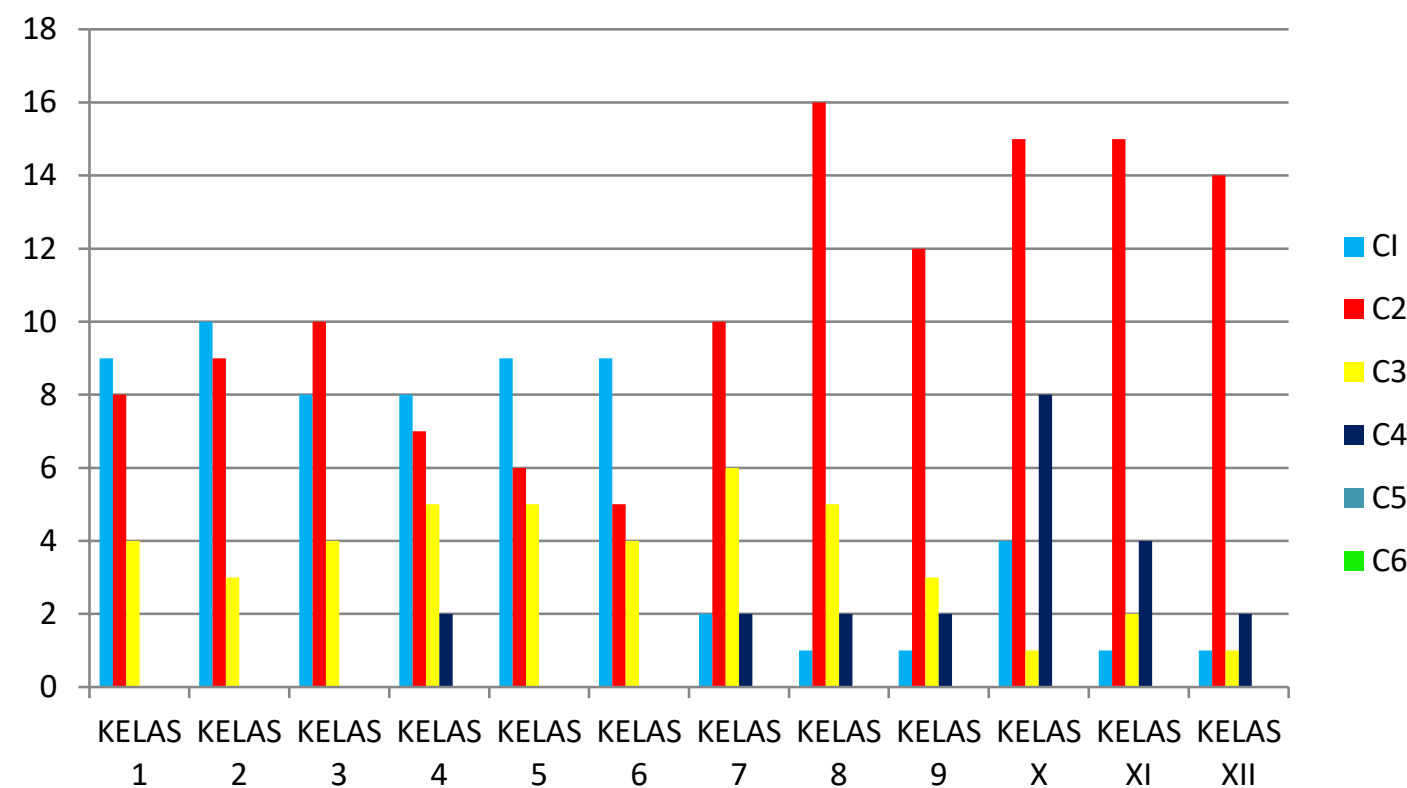

\section{Gambar 2. Distribusi kompetensi HOTS}

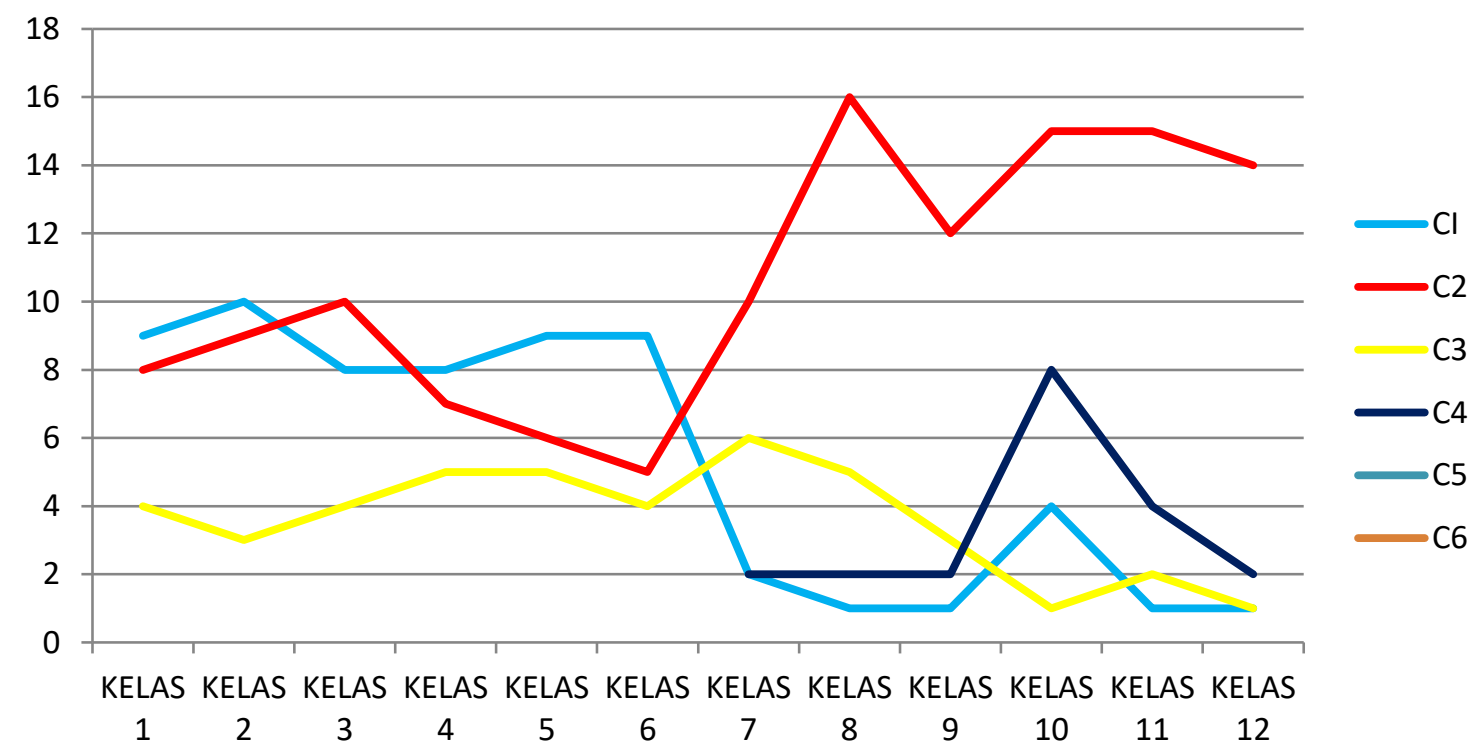

Dari gambar diagram diatas, terlihat pola distribusi kompentesi di jenjang madrasah ibtidayah sampai dengan madrasah aliyah. Dari grafik diatas dapat dianalisis bahwa kompetensi dasar yang ditawarkan oleh pemerintah dalam hal ini kementrian Agama didominasi pada tingkat kognitif C2 (memahami). Kemudian disusul C1 (Mengingat) dan C3 (menerapkan). Sementara C4 (menganalisis) jumlahnya relatif sedikit, sementara C5 (mengevaluasi) serta C6 (mencipta) belum ada sama sekali. Data ini menujukkan bahwa dari kelas 1 Madrasah Ibtidayah sampai 12 Madrasah Aliyah pembelajaran masih diarahkan pada LOTS belum sampai pada ranah HOTS.

Sementara pola distribusi kompentensi dasar ranah HOTS dalam grafik tersebut sudah menunjukkan persebaran di semua jenjang. Jenjang madrasah ibtidaiyah dengan 2 
kompentensi dasar. Di jenjang Tsanawiyah terdapat 6 kompentensi dasar. Sementara di jenjang Aliyah terdapat 14 kompetensi dasar. Persebaran kemahiran tingkat HOTS C4 (menganalisis) diatas terdapat pada kelas 4 (madrasah ibtidayah) kemudian secara berturut-turut masing-masing $2 \mathrm{Kd}$ ada dikelas 7,8,9 (madrasah Tsanawiyah), dan 10,11, dan 12 (madrasah aliyah).

Secara Umum pemerintah dalam hal ini Kementerian Agama melalui keputusanya menunujukan bahwa pola manajemen distribusi kompetensi dasar ranah HOTS pada mata pelajaran akidah akhlak mempertimbangkan jenjang atau tingkat sekolah. Semakin tinggi jenjang sekolah semakin banyak kompetensi dasar ranah HOTS nya. Ataupun sebaliknya semakin rendah jenjang sekolahnya semakin sedikit kompetensi dasar ranah HOTS nya.

\section{Gambar 3. Pola manajemen distribusi HOTS}
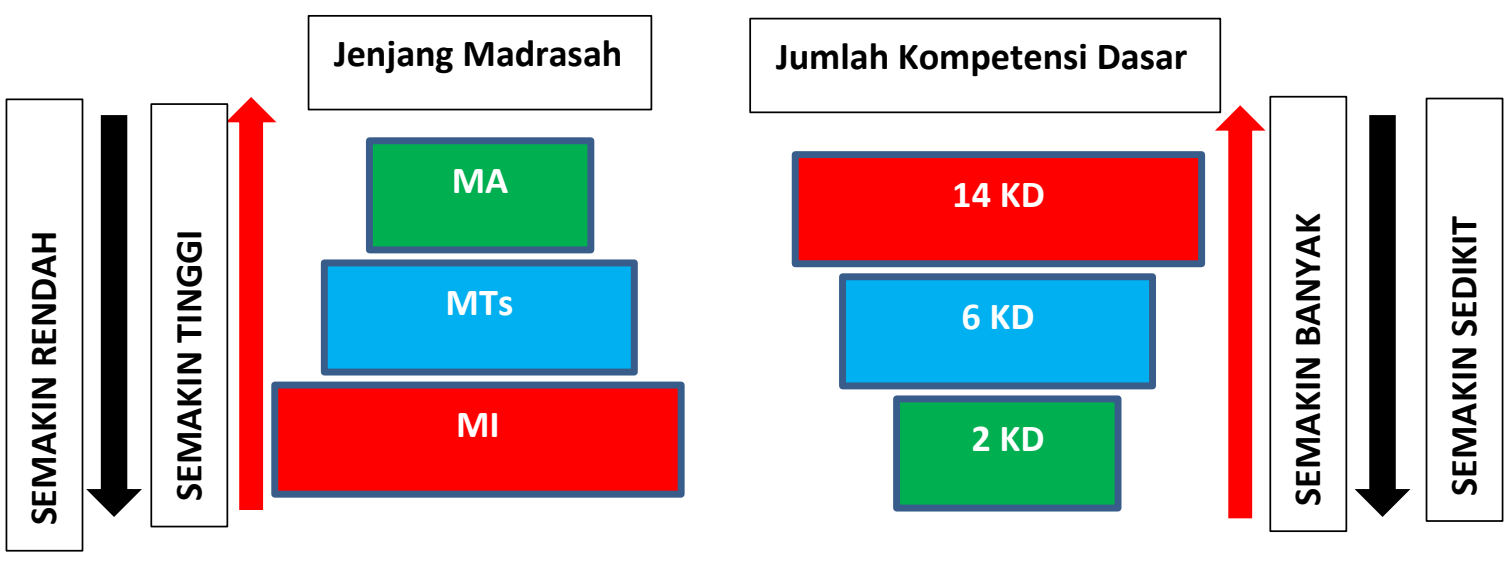

Dari analisis diatas ranah HOTS dalam KMA 165 masih relatif sedikit. Meskipun relatif sedikit tetapi menurut Eric Jensen dan Lean Nickelsen berpendapat bahwa setiap siswa dapat ditantang untuk mencapai tingkat pembelajaran yang lebih mendalam. Alasan-alasan untuk mencapai tingkat pembelajran yang lebih mendalam antara lain: (1) Membuat guru dan siswa menjadi pembelajar yang sukses pada level yang lebih mendalam. (2) Memberikan kepada guru alat pembelajaran yang mudah yang menggambarkan langkah-langkah pembelajaran yang lebih dalam. (3) Menantang semua siswa untuk sedikit melampaui tingkat kemampuan mereka sehingga sukses. (4) Menunjukkan langkah pengolahan untuk mempersiapkan pembelajaran, selama pembelajaran dan setelah pembelajaran. (5) Menggunakan setiap langkah yang memadai untuk mencapai pembelajaran yang lebih mendalam dengan semua siswa berada pada level terkini mereka. (6) Mengorganisasi langkah pembelajaran dan mendefinisikan setiap langkah secara eksplisit untuk mendapatkan aplikasi yang mudah dalam setiap rencana pelajaran. ${ }^{14}$

Ditambahkan juga bahwa aspek pengetahuan jangan dipandang sebelah mata. Aspek pengetahuan merupakan landasan dalam tujuan pendidikan. Adanya pengetahun dapat membantu pemecahan masalah atau berpikir. Hal itu dikarenakan berpikir tidak

14 Eric Jensen dan Lean Nickelsen, Deeper Learning 7 Strategi Luar Biasa untuk pembelajaran yang mendalam tak terlupakan, (Thousand Oaks corwin press, 2011), hlm. 11-12. 
bisa dilakukan didalam ruang hampa, akan tetapi harus didasarkan atas pengetahuan tentang realitas dari kemampuan. ${ }^{15}$ Jadi dapat disimpulkan bahwa pengetahuan memiliki peran penting dalam pendidikan akhlak terutama untuk membawa pembelajaran menjadi Higher Order Thingking Skill. Sekaligus menunjukan bahwa perlunya kesinambungan antara pikiran dalam hal ini pengetahuan dan juga tindakan.

Hasil analisis terhadap KMA nomor 165 diatas tentunya membuat kita tersadar. Bahawasanya sekolah atau dalam hal ini guru harus lebih kretaif dan inovatif. Dengan kompetensi dasar yang sifatnya intended dari pusat, bagaimanapun guru harus bisa mengembangkan proses pembelajaran ke dalam pembelajaran yang mengarah pada HOTS. Dengan begitu di era disrupsi ini siswa-siwa akan tetap mampu eksis dan terbiasa untuk memiliki daya nalar kritis.

\section{KESIMPULAN}

Pembelajaran akidah akhlak punya andil besar kepada mata pelajaran lain. Kompetensi Inti (KI) dan Kompetensi Dasar (KD) dalam matapelajaran akidah akhlak sebagaimana tertuang dalam Keputusan Mentri Agama No. 165 Tahun 2014 Tentang Kurikulum 2013 Mata Pelajaran PAI dan Bahasa Arab Pada Madrasah sudah diarahkan pada HOTS. Hanya saja jumlah Kompetensi Dasar (KD) yang sifatnya intended dari pemerintah berkaitan dengan Higher Order Thinking Skill (HOTS) masih terlalu sedikit. Dari toal $255 \mathrm{KD}$ yang harus di kuasai oleh siswa selama 12 tahun mulai dari sekolah dasar/ madrasah ibtidaiyah sampai menengah atas/ madrasah aliyah hanya terdapat 22 KD yang masuk pada kategori HOTS.

Lebih rincinya Kompetensi Dasar (KD) yang ditawarkan oleh pemerintah masih didominasi pada tingkat kognitif memahami (C2). Kemudian disusul mengingat (C1) dan menerapkan (C3). Sementara ranah level HOTS menganalisis (C4) sebagai tingkatan awal HOTS jumlahnya juga masih relatif sedikit dibanding $\mathrm{C} 2, \mathrm{C} 1$, dan $\mathrm{C} 3$. level HOTS menganalisis (C4) hanya berjumlah $22 \mathrm{KD}$. Sementara mengevaluasi (C5) serta mencipta (C6) belum ada sama sekali. Namun secara eksplisit pola manajemen distribusi kompentensi dasar ranah HOTS dalam KMA No. 165 Tahun 2014 Tentang Kurikulum 2013 Mata Pelajaran PAI dan Bahasa Arab sudah menunjukkan persebaran di semua jenjang.

Dari analisis diatas dapat disimpulkan bahwa pola manajemen distribusinya semakin tinggi jenjang madrasah semakin banyak kompetensi dasar ranah HOTSnya. Dan sebaliknya semakin rendah jenjang sekolahnya semakin sedikit kompetensi dasar ranah HOTS nya.

Pemerintah selaku pencetus kebijakan harus bisa melihat fakta dilapangan dan mendengarkan suara "akar rumput". Berikan kesempatan dan ruang bagi guru untuk kreatif dan mengeksplor kegiatan pembelajaran dikelas. Kemudian pemerintah juga perlu menjembatani antara kebijakan dan implementasi dilapangan. Jangan sampai karena atas dasar "idealisme", guru dan peserta didik menjadi korban. Selain daripada itu pemenrintah dan guru harus bekerjasama untuk sama-sama menyukseskan tujuan dari pendidikan. Bentuk kerjasama ini bisa dalam kegiatan workshop, training, seminar dst. Yang kiranya dapat membatu guru dalam implementasinya.

15 Ibid, hlm.25 
Kemudian bagi guru, dirinya harus mulai sadar untuk bisa membiasakan peserta didik untuk belajar dengan pendekatan HOTS. Guru perlu membuat indikator-indikator dari KD yang diberikan pemerintah menjadi HOTS. Selain itu untuk menyukseseskan pembelajaran HOTS guru juga perlu bisa mengarahkan/menginstruksi/mensetimulus peserta didik untuk terbiasa untuk memiliki Split Thinking, Critical Thinking dan Decision maker (HOTS).

\section{DAFTAR PUSTAKA}

Eriyanto. Analisis Isi. Jakarta: Kencana, 2011.

Hadi, Saiful. "Inovasi Kurikulum Keagamaan Di SMAN 1 Pamekasan." TADRIS: Jurnal Pendidikan Islam 10, no. 1 (2015): 119-152.

https://www.kompasiana.com/darwonogurukita/5836d9dd537b610c0b8e6d20/hi herorder-thinking-skills-guru?page=all, diakses tanggal 14 November 2018, pada pukul 15.37 WIB.

Jensen, Eric dan Lean Nickelsen. Deeper Learning 7 Strategi Luar Biasa untuk pembelajaran yang mendalam tak terlupakan. Thousand Oaks: corwin press, 2011.

Kuswana, Wowo Sunaryo. Taksonomi Kognitif. Bandung: Remaja Rosdakarya Offset, 2012.

Mulyasa, E. Guru dalam Implementasi Kurikulum 2013. Bandung: Remaja Rosdakarya, 2014.

Pengembangan dan Implementasi Kurikulum 2013. Bandung: Remaja Rosdakarya, 2013.

Nusa Putra dan Santi Lisnawati. Penelitian Kualitatif Pendidikan Agama Islam. Bandung: Remaja Rosdakarya, 2013.

Peraturan Pemenrintah Nomor 32 Tahun 2013 tentang SNP.

Solichin, Mohammad Muchlis. "Pendidikan Agama Islam Berbasis Kesetaraan Gender." TADRIS: Jurnal Pendidikan Islam 1, no. 1 (2006).

Suharsimi Arikonto. Prosedur Penelitian; Suatu Pendekatan Praktik. Jakarta: PT. Rineka Cipta, 2013.

Suhartono, Irawan. Metode Penelitian Sosial. Bandung: Remaja Rosdakarya, 2008.

Sulistyo, Basuki. Metode penelitian. Jakarta: Penaku, 2010.

Thoha, Mohammad. "Pembelajaran Bahasa Arab dengan Pendekatan Manajemen Berbasis Sekolah." OKARA: Jurnal Bahasa dan Sastra 6, no. 1 (2012).

Wahid, Abdul hamid, 2018. Integrasi Higher Order Thinking Skill (HOTS)

Dengan Model Creative Problem Solving, MODELING: Jurnal Program Studi PGMI Volume 5, Nomor 1, Maret 2018. 